\title{
Movimentos de Teorias em Campos Interdisciplinares: a Inserção de Michel Foucault na Contabilidade
}

\author{
Edson Luiz Riccio \\ Octavio Ribeiro de Mendonça Neto \\ Marici Cristine Gramacho Sakata
}

\section{Resumo}

As obras de Michel Foucault têm sido referenciadas em diversos campos do conhecimento e tal influência tem sido notada também na contabilidade. Este artigo utiliza o modelo conceitual de Pierre Bourdieu sobre campos do conhecimento para analisar a natureza da inserção de Foucault no pensamento contábil por meio do levantamento e da sistematização de artigos publicados em revistas científicas internacionais de contabilidade. Esta análise é fundamental para se conhecer a formação e evolução teórica do campo da contabilidade e suas implicações práticas. O objetivo é discutir quando Foucault começou a ser referenciado, a existência de recepção ou recusa pelos pesquisadores, a relação entre o campo em que foi produzido e o campo em que foi recebido e para quais questões se tem tornado indispensável. O método utilizado foi a pesquisa descritiva. Do total de 66 revistas científicas, foram identificados 113 artigos em 14 revistas com referência a Foucault. Foi possível verificar que $40 \%$ dos artigos são fundamentados em Foucault. Desses, $52 \%$ tratam do aspecto disciplinar da contabilidade, seguidos pela questão referente ao discurso-linguagem-narrativa (22\%). Os demais $60 \%$ citam Foucault como referência incidental a seus conceitos.

Palavras-chave: Michel Foucault; Bourdieu; Lotka; Teoria Contábil; Contabilidade Crítica.

\begin{abstract}
Michel Foucault's works have been referenced in several fields of knowledge and such influence has also been noticed in accounting. This article is based on Pierre Bourdieu's conceptual model to analyze the nature of Foucault's insertion in accounting thinking through the collection and systematization of articles published in international scientific accounting journals. The objective is to address at what point in time Foucault started acting as a reference, the how he was accepted or refused by researchers, the relationship between the field in which references were produced and the field in which they were received, and to which subjects he has turned to be indispensable. The method used was descriptive research. Of a total of 66 scientific journals related with accounting research, with 6.428 published articles, 113 articles were identified in 14 magazines with reference to Foucault. It was possible to verify that $40 \%$ of the articles are based in Foucault. Of that total, $52 \%$ deals with disciplinary aspects of accounting, followed by the subject regarding speechlanguage-narrative (22\%). The remaining - 60\% - mentions Foucault as incidental or topical reference to their concepts.
\end{abstract}

Key words: Michel Foucault; Bourdieu; Lotka; Accounting Theory; Critical Accounting. 


\section{INTRODUÇÃO}

As diversas áreas que fazem parte das ciências sociais têm como característica a interdisciplinaridade, ou seja, conceitos e teorias de diferentes disciplinas integramse entre si, e em conjunto dão origem a uma nova disciplina. Esta é umas das características que definem a Contabilidade. Teorias e idéias são transportadas e traduzidas de uma área para outra. Assim ocorreu, por exemplo, com as teorias econômicas, matemáticas e organizacionais que foram transportadas para a Contabilidade e que, por um conjunto de fatores, foram sendo aceitas pelos membros que compõem o corpo desse campo de conhecimento, conseqüentemente, passando a fazer parte dele.

O momento em que uma teoria é levada do campo em que foi gerada para outro nem sempre é facilmente percebido, nem sempre ocorre em horizonte curto de tempo. A visão sistêmica traz à luz esses movimentos e permite identificar esta "tradução de idéias" (Latour, 1987), enquanto o processo está em desenvolvimento, porém deixa também questões para serem respondidas futuramente.

Este estudo contribui para identificar o desenvolvimento de uma nova área de pesquisa na Contabilidade Crítica por meio de movimentos de teorias entre campos. Mostra como as teorias do filósofo francês Michel Foucault têm sido utilizadas desde 1986 pelos pesquisadores desta área, para explicar o uso da contabilidade como instrumento disciplinador e de poder nas organizações e na sociedade. Busca esclarecer e fundamentar, teórica e empiricamente, a entrada e o estabelecimento de um autor, no caso Michel Foucault, no pensamento contábil, levando em consideração o sistema de relações existentes no campo científico fundamentado em Bourdieu (1976). Esta análise é fundamental para se conhecerem a formação e a evolução teórica do campo da contabilidade e suas implicações práticas. Michel Foucault publicou suas obras entre 1954 e 1984. Suas idéias vêm desde então causando grande impacto, tanto nas ciências humanas como ciências sociais, e têm sido referenciadas em larga escala, tanto no campo filosófico, onde têm sua origem, como nos campos da história, da psicologia, da educação, dos estudos organizacionais e da contabilidade, entre outros.

O objetivo é analisar em que época Foucault começa a ter suas teorias referenciadas na área contábil, qual a sua contribuição, recepção ou recusa pelos pesquisadores, e a relação entre o campo em que foi produzido e o campo em que foi recebido, ou seja, de que forma o pensamento de Foucault se tem tornado 
indispensável na discussão de determinadas questões da contabilidade. Para tanto será necessário, de início, distinguir os tipos de leituras que estão sendo feitas pelos leitores/autores, ou seja, compreender as condições de recepção das idéias de Foucault no pensamento contábil, assim como das categorias e postulados que as sustentam. Para a realização da pesquisa descritiva o instrumento utilizado foi a meta-análise. A meta-análise, por meio da leitura da produção científica, é passo fundamental para se obter uma visão sistêmica da presença de um autor em outro campo científico, de forma estruturada.

O artigo discute, em primeiro lugar, de que forma a questão desta pesquisa contribui para a ciência e, através da literatura, identifica os esforços que estão sendo feitos nesta mesma direção. É feita, também, uma breve introdução às principais obras de Foucault e respectivas contribuições. Na segunda parte é estabelecido o quadro teórico e metodológico. Os resultados são apresentados seguidos das conclusões e algumas respostas às questões levantadas.

\section{Pressupostos Teóricos das Ciências Sociais}

Como na maioria das ciências sociais, a contabilidade também tem suas pesquisas conduzidas a partir de pressupostos referentes à natureza das ciências sociais. Riahi-Balkaoui (1997, p. 17) analisou as perspectivas do pensamento contábil segundo as hipóteses de Stephen Pepper e Burrell e Morgan. Pepper definiu quatro pressupostos gerais para analisar o conhecimento: (1) Formismo (realismo), que inclui as teorias analíticas e dispersivas. (2) Mecanismo (naturalismo/ materialismo), que inclui as teorias analíticas e integrativas. (3) Contextualismo (pragmatismo), que inclui as teorias sintéticas e dispersivas. (4) Organicismo (idealismo), que inclui as teorias sintéticas e integrativas. As dimensões subjetivoobjetivas e dimensões regulativo-radicais são analisadas por Burrell e Morgan (1979), e consistem em quatro paradigmas distintos, que são formas de visões da realidade a serem utilizadas na análise das teorias sociais, incluindo a contabilidade, a saber: (1) Humanismo radical, que explica a ordem social a partir de pressupostos nominalistas, antipositivistas, voluntaristas e ideográficos e enfatiza as formas de mudança radicais, reduzindo críticas filosóficas às metodologias normativas. (2) Estruturalismo radical, que busca mudanças radicais, emancipação e potencialidades utilizando-se de análises com ênfase em contradições, conflitos e modos de dominação. (3) Interpretativo, que objetiva entender a experiência subjetiva do indivíduo envolvido na preparação, comunicação, verificação e uso de informação contábil e (4) Funcionalista, que focaliza a explicação da ordem social, em que a contabilidade desenvolve o seu papel e vê o fenômeno da contabilidade como relações concretas do mundo real, possuidoras de 
regularidades e relacionamentos causais amenizáveis por explicações e previsões científicas (Riahi-Balkaoui, 1997, pp. 31-35).

As teorias contábeis têm-se baseado predominantemente na visão funcionalista com tentativas pontuais nas demais visões. O paradigma funcionalista na contabilidade focaliza o estabelecimento de funções necessárias para uma operação eficiente da organização. A crítica feita a este paradigma é que na contabilidade não se assume a teoria como sendo historicamente relativa. A maioria dos artigos publicados é caracterizada por métodos quantitativos, hipotético-dedutivos e generalizações. Chua (1986) afirma que uma mudança no conjunto de pressupostos potencia pesquisas novas e diferentes. Para a autora, as duas alternativas para a visão de mundo e seus pressupostos são a crítica e a interpretativa. No entanto a pesquisa contábil segue um conjunto restrito de crenças, valores e técnicas já aceitos pelos pares, o que acaba impossibilitando outros tipos de discussões teóricas.

\section{Desenvolvimento dos Pressupostos da Pesquisa Contábil}

A partir das definições das possíveis visões de mundo das ciências sociais e da sociedade, percebe-se que o pensamento contábil se tem desenvolvido baseado fortemente em pressupostos funcionalistas (Riahi-Balkaoui, 1997).

Considerando a visão de Chua (1986), o espaço para pesquisas com diferentes pressupostos ainda é limitado. No entanto percebe-se um apoio maior em publicações como Accounting, Auditing \& Accountability Journal, Accounting, Organization and Society (AOS), Critical Perspectives in Accounting, entre outras. Identificar tais perspectivas nos estudos contábeis foi tarefa de Baxter e Chua (2003) que, a partir da análise dos artigos publicados na AOS, identificaram as seguintes abordagens de pesquisa em contabilidade gerencial: non-rational design school, naturalistic research, radical alternative, institutional theory, structuration theory, foucaultian approach and latourian approach. Estudos desta natureza possibilitam conhecer o desenvolvimento histórico do pensamento contábil e suas fontes de influência. Neste sentido, Wells (1976) identificou a transição de pesquisas normativas e apriorísticas para as empíricas, ocorridas nas décadas de 1960 a 1970. Watts e Zimmerman (1990), por sua vez, identificaram que as pesquisas na década de 1980 eram predominantemente positivistas.

Os trabalhos com perspectivas foucaultianas foram identificados na contabilidade por Baxter e Chua (2003) e Gendron e Baker (2005). Ambos analisaram os artigos publicados na AOS e, enquanto Baxter e Chua (2003) identificou oito artigos cujo referencial teórico era foucaultiano, Gendron e Baker (2005) levantaram todas as referências a Foucault nos estudos publicados pela AOS. 


\section{Movimentos de Teorias em Campos Interdisciplinares}

Definidos os pressupostos da pesquisa contábil, suas características e vertentes, pode-se compreender como um autor, ou melhor, as idéias de um autor entram em campo, ou então quando um autor passa a ser o fundamento teórico para se discutirem determinadas questões. Gendron e Baker (2005) analisaram esta questão, baseando-se nos pressupostos teóricos de Latour, referentes à sociologia da tradução e redes de suporte e também questionaram os acadêmicos sobre como e quando se deu o primeiro contato com as obras de Michel Foucault.

Este artigo, por outro lado, pretende analisar esta questão a partir da perspectiva de campo científico de Bourdieu (1976). A noção de campo significa para Bourdieu um espaço social de dominação e de conflitos, onde os indivíduos agem segundo sua posição social neste espaço e guiados por uma estratégia política de investimento objetivamente orientada (p. 127).

No pressuposto de campo científico de Bourdieu (1976, p. 124) "todas as práticas do campo científico estão orientadas para a aquisição de autoridade científica (prestígio, reconhecimento, celebridade etc.); o que é chamado de interesse por uma atividade científica (uma disciplina, um setor dessa disciplina, um método etc.) tem sempre uma dupla face". Campo é o espaço onde as relações sociais estão distribuídas na forma de capital, seja cultural ou simbólico. Os participantes de cada campo possuem capacidades de desempenhar funções e a prática das lutas para atingir seus objetivos e garantir sua sobrevivência. Para Bourdieu, tais relações definem-se independentemente da consciência humana. Na estrutura do campo (hierarquia de posições, tradições, instituições e história) os participantes adquirem um conjunto de disposições para agir de acordo com as possibilidades existentes dentro desta estrutura objetiva, que é chamada por ele de habitus. Bourdieu trabalha os conceitos de campo, capital e habitus para explicar as interações na sociedade. Neste artigo, a utilização da noção de campo segundo Bourdieu, como referencial teórico, permite iniciar e fundamentar a exploração das interações dos pesquisadores com as estruturas, agentes e símbolos.

A partir dessa noção de campo, para se compreender uma obra deve-se compreender inicialmente a produção, o campo da produção, a relação entre o campo em que ela é produzida e o campo em que é recebida ou, mais precisamente, a relação entre as posições do autor e do leitor em seus respectivos campos (Bourdieu, 1997, p. 13). Também é necessário entender o que leva um pesquisador a buscar fundamentação em outros campos, as intenções implícitas nesta ação, os possíveis retornos obtidos pelo esforço adicional em desenvolver pesquisas, cujos pressupostos ainda não são facilmente aceitos pelos pares e suas limitações. 
Esta análise das publicações é passo fundamental para distinguir os tipos de leitura sendo feita pelos leitores/autores, a posição dos autores e dos leitores em seus respectivos campos (Bourdieu, 1997) e a compreensão das condições de recepção da obra de Foucault no pensamento contábil, (conforme termo definido por Wacquant, 1990 como citado em Watts \& Zimmerman, 1990) e ainda para compreender como o pensamento de Foucault se tem estabelecido na área contábil.

\section{As Obras de Foucault}

O filósofo francês Michel Foucault (1926-1984) é autor de uma obra que tem influenciado diversos campos do conhecimento, em particular a história, a filosofia, a sociologia e a psicologia, entre outros. Foucault cursou na França a prestigiosa École Normale Supérieure e posteriormente formou-se em filosofia e psicologia. Foi aluno de Maurice Merleau-Ponty e Louis Althusser e contemporâneo de Gilles Deleuze e Roland Barthes. O primeiro livro de Foucault publicado foi Folie et déraison em 1961. Em 1963 publicou Naissance de la clinique, e em 1966, um dos mais conhecidos, Les mots et les choses. Outras obras de grande destaque publicadas posteriormente e também publicadas no Brasil foram: A arqueologia do saber, A Ordem do discurso, Vigiar e punir e História da sexualidade. Foucault fez parte do corpo de professores do Collège de France, onde lecionou temas na sua área de História do Sistema de Pensamento. Seus últimos trabalhos e biografia foram escritos nos Estados Unidos, onde viveu os últimos anos de sua vida. Seu trabalho é freqüentemente associado ao pós-modernismo, pós-estruturalismo e estruturalismo; mas ele próprio não aceitava que seu trabalho fosse rotulado. Suas teorias estão basicamente relacionadas ao poder e às relações entre poder e conhecimento.

\section{Metodologia da Pesquisa}

Este artigo analisa a natureza e o impacto da inserção de Foucault no pensamento contábil por meio do levantamento e da sistematização de artigos publicados em revistas científicas de contabilidade, onde o autor é referenciado. O método de pesquisa utilizado foi quantitativo e qualitativo, baseado na meta-análise, na leitura completa dos artigos e na bibliometria.

A meta-análise, após a definição do referencial teórico, atua como estratégia de pesquisa que deve considerar: o domínio da pesquisa, as variáveis e os critérios de inclusão (Glass, McGaw, \& Smith, 1981). Trata-se de importante forma lógica de gerar consenso e generalizações sobre um fenômeno. Hek, Langton e Blunden 
(2000 como citado em Booth, 2001) como citado em definem meta-análise como a parte quantitativa de uma visão mais ampla denominada meta-síntese. Este tipo de estratégia de pesquisa permite uma visão geral dos trabalhos publicados em uma área específica, quando já há quantidade significativa de pesquisas publicadas. Assim, a meta-análise, feita nesta pesquisa, considerou o levantamento e a sistematização dos estudos publicados que possuem as características propostas nos objetivos dela.

Além da sistematização, considerou-se a necessidade de complementar esta estratégia quantitativa com a leitura completa dos artigos e a distinção do tipo de leitura feita pelos autores dos artigos selecionados. Para distinguir os tipos de leitura, utilizou-se a tipologia de Chartier (1985), que define as apropriações de autores de outra área em três categorias.

1. Apropriação incidental, em que não é possível estabelecer relação entre a argumentação empreendida no texto e o referencial, guardando relação muito tênue com o argumento desenvolvido.

2. Apropriação conceitual tópica, caracterizada pelo fato de deixar entrever a utilização, conquanto não sistemática, de citações e eventualmente de conceitos do autor. As apropriações são mobilizadas para reforçar argumentos ou resultados obtidos e desenvolvidos, em quadro terminológico que não necessariamente é o do autor.

3. Apropriação do modo de trabalho, maneiras de apropriação reveladoras da utilização sistemática de noções e conceitos do autor, com preocupação central no modus operandi da teoria.

Para a pesquisa bibliométrica, foi utilizada a Lei de Lotka, com o objetivo de determinar a produtividade por autor (Macias-Chapula, 1998; Verbeek, Debackere, Luwel, \& Zimmermann, 2002).

A pesquisa bibliométrica efetuada permite quantificar os artigos publicados, a média de artigos por autor, a concentração, a distribuição temporal dos artigos e a publicação deles nos diversos periódicos. A produtividade dos autores pode ser analisada pela lei de Lotka (1926): uma constatação empírica da produtividade científica que relaciona o número de autores ao número de contribuições feitas por cada autor, em uma escala logarítmica. Esta lei afirma que o número de autores que produziu 2 artigos é igual a $1 / 4$ dos que produziram 1 ; o número dos que produziram 3 é igual a 1/9; o número dos que produziram 4 é igual a 1/16 e assim por diante, ou seja: $a_{n}=\frac{a_{1}}{n^{2}}$ onde: 
$a_{1}=$ Número de autores que publica um único artigo

$a_{n}=$ Número de autores que publica $n$ artigos

$n=$ Número de artigos

Esta Lei foi estabelecida empiricamente por Lotka, na década de 1920, para as produções científicas em química e física e, posteriormente, generalizada para outros ramos do conhecimento. O que se observa nessas generalizações é que se estabelece, por meio de uma regressão linear, um valor diferente para o expoente de $n$, que no caso de Lotka é de 2. Estudos sobre a produção contábil têm sido feitos por diversos autores, como Oliveira (2002), Otchere (2003), Shields (1997); a bibliometria como instrumento de análise tem sido amplamente utilizada, como em Mcmillan e Hicks (2001), Mcmillan e Hamilton (2000) e Tonelli, Caldas, Lacombe e Tinoco (2003). No caso de Contabilidade em geral, Chung, Cox e Pak (1992) examinaram 14 periódicos científicos destinados a divulgar a pesquisa acadêmica em contabilidade, todos eles publicados em Inglês, no período de 1968 a 1988. Durante esses 21 anos, estes periódicos publicaram 5580 artigos de um total de 3422 autores. Os resultados obtidos revelaram a existência de forte regularidade bibliométrica na literatura contábil do período: estes autores encontraram um valor de 1,872 para o expoente $c$ da Lei de Lotka generalizada, $a_{n}=\frac{a_{1}}{n^{c}}$ o que mostra que a literatura contábil do período se vem adequando bem ao modelo de Lotka. No caso brasileiro, Riccio, Sakata, Mendonça e Cardoso (2005) levantaram a pesquisa em contabilidade publicada em periódicos nacionais classificados com o conceito A pela Capes - Coordenação de Aperfeiçoamento de Pessoal de Nível Superior. Do total de 2037 artigos publicados por estes periódicos, foram encontrados 60 relacionados à pesquisa contábil, escritos por 77 autores. Para essa amostra, os autores encontraram um valor de 2,54 para o expoente $c$ da Lei de Lotka generalizada. Este resultado revela que, embora a pesquisa brasileira em contabilidade publicada em periódicos classificados com o conceito A pela CAPES seja modesta, e com produtividade mais baixa, também se vem adequando bem ao modelo de Lotka. Ainda no caso brasileiro, Leal, Oliveira e Soluri (2003) pesquisaram a produção brasileira em finanças, encontrando um valor de 2,44 para o expoente $c$. Valores menores que 2 significam uma produtividade maior do que a estabelecida pela Lei de Lotka, normalmente adotada como padrão, enquanto valores maiores que 2 significam uma produtividade menor. Em outras palavras, para valores menores que 2, a assimetria é maior e, portanto, o conhecimento está mais concentrado em menor número de autores. Para valores maiores que 2 a assimetria é menor e, portanto, o conhecimento está menos concentrado. Se a amostra em apreço, que totaliza 132 autores, seguisse a Lei de Lotka, conforme descrita acima, teríamos 80 autores 
com uma única publicação $(60,8 \%$ de 113$)$ e não os 102 (77,3\%) observados. Isto significa uma produtividade inferior ao padrão internacional constatado por Lotka. Para atender aos objetivos de discutir em que ocasião Foucault se estabeleceu na área contábil, assim como sua recepção ou recusa pelos pesquisadores, e de que forma o seu pensamento se tem tornado indispensável na discussão de determinadas questões da contabilidade, utilizou-se a pesquisa descritiva. $\mathrm{Na}$ primeira etapa foram selecionadas as revistas científicas, objeto do estudo (ver Tabela 2). Em uma segunda etapa foram analisados os artigos. Todo o processo de classificação dos dados foi realizado pelos três autores, objetivando melhor ajuste de definições e redução das incertezas inerentes a esse tipo de classificação. O instrumento utilizado para a leitura dos textos teve como base os seguintes itens: título, autor, instituição, tema, contexto, questão da pesquisa, conclusão e forma de leitura de Foucault.

\section{Amostra}

Para esta pesquisa optou-se pela análise de artigos publicados em revistas em língua inglesa com peer review e de renome internacional. A decisão deu-se pela necessidade de eliminar vieses e quadros teóricos que não tenham sido selecionados por um comitê científico/editorial, fato que ocorre nos trabalhos ainda em desenvolvimento. Para acesso aos artigos na íntegra foi utilizada a base de dados PROQUEST: ABI/INFORM Global, que conta com um total de 2.632 títulos, e SCIENCE DIRECT ACCESS, com um total de 1.800 Títulos. Para a seleção dos artigos foram utilizadas as seguintes palavras - chave: Foucault, Foucauldian, Foucaultian foucauldian ou foucaultian. Na base de dados PROQUEST foram consultadas as duas formas disponíveis, ou seja: Citation and Abstract e Citation and Document Text. Na base de dados SCIENCE DIRECT ACCESS foi consultada a única forma disponível, ou seja: Abstract, Titles, Keywords and Authors.

Nessas bases de dados foram pesquisados 6.128 exemplares de 66 periódicos relacionados à área contábil e foram encontrados 113, publicados em 14 desses periódicos. De acordo com o período abrangido pelos bancos de dados para cada periódico, a data mais antiga é a de outubro de 1968 e se refere a Management Accounting Research, seguida pela Accounting Review, cujos exemplares estão disponíveis a partir de 1971. Dos 14 periódicos que publicaram algum artigo fundamentado em Foucault ou com alguma referência a suas obras, o total de exemplares disponíveis para acesso no período em estudo é de 1.672, conforme se indica na Tabela 2. Por exemplo, na Accounting and Business Research a pesquisa foi realizada do volume 4, de 1973, ao 
volume 34 número 3, de 2004. Neste período foram publicados 174 exemplares, dos quais 4 continham artigos com referências a Foucault. $O$ total de artigos também foi de 4, ou seja, 1 por exemplar. Em alguns casos temos mais de 1 artigo por exemplar. Do total de 113 artigos foram obtidas cópias completas de 95 artigos.

\section{Tabela 1: Amostra e Total de Artigos Analisados}

\begin{tabular}{|c|c|c|c|c|c|c|c|c|}
\hline & Título do Periódico & País & $\begin{array}{l}\text { Data } \\
\text { Inicial }\end{array}$ & $\begin{array}{l}\text { Data } \\
\text { Final }\end{array}$ & $\begin{array}{c}\text { Total de } \\
\text { Exemplares } \\
\text { disponíveis } \\
\text { para acesso } \\
\text { (A) }\end{array}$ & $\begin{array}{l}\text { Total de } \\
\text { Exempla- } \\
\text { res com } \\
\text { Artigos } \\
\text { (B) }\end{array}$ & $\begin{array}{l}\text { Total de } \\
\text { Artigos }\end{array}$ & $\begin{array}{c}\mathrm{B} / \mathrm{A} \\
\%\end{array}$ \\
\hline 1 & $\begin{array}{l}\text { Accounting and Business } \\
\text { Research }\end{array}$ & Inglaterra & 1973 & 2004 & 174 & 4 & 4 & 2,30 \\
\hline 2 & $\begin{array}{l}\text { Accounting, Auditing \& } \\
\text { Accountability Journal }\end{array}$ & Inglaterra & 1992 & 2004 & 62 & 36 & 60 & 58,06 \\
\hline 3 & $\begin{array}{l}\text { Accounting, Organizations } \\
\text { and Society }\end{array}$ & Inglaterra & 1976 & 2005 & 151 & 8 & 8 & 5,30 \\
\hline 4 & $\begin{array}{l}\text { Canadian Accounting } \\
\text { Perspectives }\end{array}$ & Canadá & 2001 & 2004 & 6 & 2 & 2 & 33,33 \\
\hline 5 & The CPA Journal & $\begin{array}{l}\text { Estados } \\
\text { Unidos }\end{array}$ & 1981 & 2004 & 597 & 1 & 1 & 0,18 \\
\hline 6 & $\begin{array}{l}\text { Critical Perspectives on } \\
\text { Accounting (Elsevier) }\end{array}$ & $\begin{array}{l}\text { Estados } \\
\text { Unidos }\end{array}$ & 1990 & 2005 & 69 & 19 & 22 & 27,54 \\
\hline 7 & $\begin{array}{l}\text { Financial Accountability \& } \\
\text { Management }\end{array}$ & Inglaterra & 1985 & 2004 & 107 & 1 & 1 & 0,93 \\
\hline 8 & $\begin{array}{l}\text { The International Journal of } \\
\text { Accounting }\end{array}$ & Inglaterra & 1971 & 2004 & 66 & 1 & 1 & 1,52 \\
\hline 9 & $\begin{array}{l}\text { The Irish Accounting } \\
\text { Review }\end{array}$ & Irlanda & 2004 & 2004 & 1 & 1 & 1 & $\begin{array}{r}100,0 \\
0 \\
\end{array}$ \\
\hline 10 & $\begin{array}{l}\text { Journal of Accounting } \\
\text { Literature }\end{array}$ & $\begin{array}{l}\text { Estados } \\
\text { Unidos }\end{array}$ & 1982 & 2003 & 22 & 2 & 2 & 9,09 \\
\hline 11 & $\begin{array}{l}\text { Journal of Business Finance } \\
\& \text { Accounting }\end{array}$ & Inglaterra & 1974 & 2004 & 250 & 1 & 1 & 0,40 \\
\hline 12 & $\begin{array}{l}\text { Journal of Management } \\
\text { Accounting Research }\end{array}$ & $\begin{array}{l}\text { Estados } \\
\text { Unidos }\end{array}$ & 1994 & 2003 & 13 & 2 & 3 & 15,38 \\
\hline 13 & $\begin{array}{l}\text { Management Accounting } \\
\text { Research }\end{array}$ & Inglaterra & 1992 & 2004 & 51 & 2 & 2 & 3,92 \\
\hline 14 & $\begin{array}{l}\text { Managerial Auditing } \\
\text { Journal }\end{array}$ & Inglaterra & 1992 & 2004 & 103 & 4 & 5 & 3,88 \\
\hline & TOTAL & & & & 1672 & 84 & 113 & 3,76 \\
\hline
\end{tabular}

\section{Resultados da Pesquisa - Participação de Foucault na CONTABILIDADE}

Os resultados foram obtidos por meio da meta-análise dos dados, da leitura completa dos artigos e do cálculo da lei de Lotka. A meta-análise considerou o levantamento e a sistematização dos estudos publicados que contêm as 
características propostas no objetivo deste trabalho. Além da sistematização, complementou-se a análise com a leitura completa dos artigos e distinção do tipo de leitura feita pelos autores dos artigos selecionados de acordo com a tipologia de Chartier (1985), ou seja, 1. Apropriação incidental. 2. Apropriação conceitual tópica e 3. Apropriação do modo de trabalho. Para a pesquisa bibliométrica foi utilizada a Lei de Lotka para determinar a produtividade por autor (Macias Chapula, 1998; Verbeek et al., 2002).

\section{Análise Quantitativa - Meta-análise}

Do total de 66 revistas científicas (periódicos) com 6.428 artigos publicados, foram identificados, por meio da metodologia sumariada anteriormente, 113 artigos em 14 revistas com referência a Foucault feitas no título ou abstract. Esses 113 artigos foram publicados por 132 autores, o que resulta uma média de 0,86 artigos por autor, significando que a maioria foi escrita em co-autoria. $\mathrm{O}$ primeiro artigo localizado foi publicado em 1986 na Accounting, Organization and Society - v.11, n. ${ }^{\circ}$ 2, por Hoskin e Macve com o título de Accounting and the Examination: A Genealogy of Disciplinary Power, e o último em 2005, na Critical Perspectives on Accounting - v. 16, n. 3 publicado por Birkin, Edwards e Woodward com o título de Accounting's Contribution to a Conscious Cultural Evolution: an End to Sustainable Development.

Conforme já salientado, dos 66 periódicos examinados, 14 contêm artigos referenciados a Foucault. Destes 14 periódicos foram examinados 1.672 exemplares, dos quais 84 contêm 113 artigos referenciados a Foucault, com uma média de 1.345 artigos por exemplar. A análise por periódico revela uma presença maior de artigos na Accounting, Auditing \& Accountability Journal e na Critical Perspectives on Accounting, com 60 e 22 artigos respectivamente do total de 113 publicados, sendo os dois periódicos em conjunto responsáveis por 72,57\% da produção do período.

Em termos geográficos, observa-se que dos 14 periódicos em apreço, 8 são publicados no ReinoUnido; 4 nos Estados Unidos, 1 no Canadá e 1 na Irlanda. Isto revela uma concentração de publicação nos periódicos europeus. Quanto à distribuição temporal, observa-se na Tabela 2 uma produção mais numerosa a partir de 1992, com volumes significativos em 1994, 1996, 2002 e 2003. 
Tabela 2: Distribuição Temporal dos Artigos

\begin{tabular}{|c|c|c|}
\hline Ano & N. $^{\mathbf{0}}$ de Artigos & $\mathbf{\%}$ \\
\hline 1986 & 2 & 1,77 \\
\hline 1987 & 2 & 1,77 \\
\hline 1988 & 1 & 0,88 \\
\hline 1989 & 1 & 0,88 \\
\hline 1990 & 2 & 1,77 \\
\hline 1991 & 0 & - \\
\hline 1992 & 5 & 4,42 \\
\hline 1993 & 9 & 7,96 \\
\hline 1994 & 12 & 10,62 \\
\hline 1995 & 8 & 7,08 \\
\hline 1996 & 11 & 9,73 \\
\hline 1997 & 5 & 4,42 \\
\hline 1998 & 10 & 8,85 \\
\hline 1999 & 4 & 3,54 \\
\hline 2000 & 7 & 6,19 \\
\hline 2001 & 2 & 1,77 \\
\hline 2002 & 12 & 10,62 \\
\hline 2003 & 13 & 11,50 \\
\hline 2004 & 6 & 5,31 \\
\hline 2005 & 1 & 0,88 \\
\hline Total & 113 & 100,00 \\
\hline & & \\
\hline
\end{tabular}

\section{Análise Comparativa da Produtividade dos Autores}

\section{A Generalização da Lei de Lotka}

Da mesma forma que Chung et al. (1992), Leal et al. (2003) e Riccio et al. (2005) apresenta-se a seguir uma estimativa para o coeficiente $c$ da Lei de Lotka genérica expressa por

$a_{n}=a_{1} \cdot \frac{1}{n^{c}}$

Conforme já salientado no item Análise da Produtividade dos Autores deste trabalho, este coeficiente $c$ pode ser estimado por regressão linear. Para a amostra em questão, o coeficiente $c$ calculado foi em 2,02. O coeficiente de correlação entre as variáveis em exame foi de 0,9632 , o que significa um grau de confiança de $96 \%$. O coeficiente de determinação $\mathrm{R}^{2}$ resultou 0,9277 , o que representa um poder explicativo satisfatório do modelo. Desta forma, pode-se concluir que o 
número de autores com mais de uma publicação para a amostra de periódicos em apreciação pode ser estimado a partir da equação abaixo:

$a_{n}=a_{1} x \frac{1}{n^{2,02}}$

Cabe observar que este coeficiente $c$ de 2,02 é pouco maior que o padrão de Lotka e que o calculado por Chung et al. (1992), mas é inferior ao calculado por Leal et al. (2003) $(2,44)$ e Riccio et al. (2005) $(2,54)$. Uma comparação entre os dados do estudo atual e os padrões de Chung et al. (1992) pode ser observada na Tabela 3 a seguir:

Tabela 3: Coeficiente $c$

\begin{tabular}{|c|c|c|c|}
\hline \multicolumn{1}{|c|}{ Estudos } & $\begin{array}{c}\text { Dados de } \\
\text { Chung, Cox e Pak }\end{array}$ & Padrão Lei de Lotka & $\begin{array}{c}\text { Dados da Amostra em } \\
\text { Questão }\end{array}$ \\
\hline$c$ & 1,87 & 2,00 & 2,02 \\
\hline $\begin{array}{l}\text { \% de Autores } \\
\text { com um único artigo } \\
\text { publicado }\end{array}$ & 57,7 & 60,8 & 76,12 \\
\hline
\end{tabular}

A Tabela 4 apresenta uma comparação entre os dados observados e os padrões internacionais constatados por Lotka.

Tabela 4: Comparação da Produtividade entre os Dados da Amostra em Questão e o Padrão Internacional

\begin{tabular}{|c|c|c|c|c|}
\hline \multirow{2}{*}{$\begin{array}{c}\mathbf{N}^{\circ} \mathbf{o} \text { de } \\
\text { Artigos } \\
\text { Por } \\
\text { Autor }\end{array}$} & $\begin{array}{c}\text { Dados } \\
\text { Observados }\end{array}$ & $\%$ & $\begin{array}{c}\text { Padrão } \\
\text { Internacional }\end{array}$ & $\%$ \\
\cline { 2 - 5 } & 102 & 77,27 & 80 & 60,80 \\
\hline 1 & 16 & 12,12 & 20 & 15,20 \\
\hline 2 & 8 & 6,06 & 9 & 6,80 \\
\hline 3 & 3 & 2,27 & 5 & 3,80 \\
\hline 4 & 3 & 2,27 & 3 & 2,43 \\
\hline 5 & - & - & 2 & 1,69 \\
\hline 6 & - & - & 2 & 1,24 \\
\hline 7 & - & - & 11 & 8,04 \\
\hline+7 & 132 & 100,00 & 132 & 100,00 \\
\hline Total & - & & \\
\hline
\end{tabular}


No caso do presente trabalho o expoente $c$ calculado é um pouco superior ao calculado em Lotka. Isto significa que a pesquisa contábil, fundamentada em Foucault ao longo dos últimos 13 anos, obedece aos padrões bibliométricos dos demais ramos do conhecimento, não se tratando, portanto, de modismo, mas de abordagem estabelecida dentro de uma visão mais geral denominada Contabilidade Crítica. A pesquisa sugere, ainda, que esta visão mais crítica e social da contabilidade está mais concentrada na Europa e tem-se expressado preferentemente por meio de alguns periódicos específicos como Accounting, Auditing \& Accountability Journal, Accounting, Organizations and Society e Critical Perspectives on Accounting (Elsevier) que, juntos, são responsáveis por 56\% da produção do período. Esta concentração da produção considerada mais crítica encontra paralelo, por exemplo, na literatura, onde os novos temas sempre se expressaram por meio de periódicos exclusivos, às vezes criados para tal fim.

\section{Análise Qualitativa}

Propôs-se, neste trabalho, responder, por meio da pesquisa em artigos científicos, em que ocasião Foucault se estabeleceu na área contábil e como se deu sua recepção ou recusa pelos pesquisadores.

Segundo a amostra, foram analisados 113 artigos. Do total, 5 não foram considerados na análise por se tratar de resenha de livros. Do total, 33 estão fundamentados em Foucault e 62 apenas citam o autor ou fazem breve referência a seu trabalho. Dos 18 artigos cujas cópias completas não ofereceram acesso, a pesquisa se baseou simplesmente no abstract, sendo 11 fundamentados em Foucault. Em resumo, do total de 113 artigos, 44 são fundamentados em Foucault.

$\mathrm{Na}$ amostra, os dois primeiros artigos publicados com referência a Foucault datam de 1986, um publicado na Accounting, Organization and Society (AOS) e outro na Journal of Management Accounting Research. A aceitação de publicação de um artigo é uma forma de aceitar e de até certo ponto legitimar a entrada de um novo autor na área em apreciação. Isso é confirmado pela continuidade de artigos fundamentados em Foucault publicados na Accounting, Organization and Society, nos últimos 13 anos.

Foi possível notar que apenas 5 artigos se utilizaram das idéias de Foucault como contraposição, recusando sua teoria para a análise e compreensão de determinado assunto, como Townley, B. em Managing by numbers: Accounting personnel management and creation of a mathesis publicado na Critical Perspectives on Accounting - v. 6, 1995. O autor considera deficiente a análise Foucaultiana da contabilidade, por ter-se engajado principalmente em como a contabilidade é vista e não no que é. No entanto praticamente a totalidade dos 
artigos apropria-se das idéias de Foucault, configurando a recepção e aceitação do autor no pensamento contábil. Dois artigos são de autores que recusam as idéias de Foucault, quando estas são utilizadas como única forma de compreensão da realidade, porém as aceitam quando unidas a outras.

Quanto à relação entre o campo em que foi produzido e o campo em que foi recebido, ou seja, de que forma o pensamento de Foucault se tem tornado indispensável na discussão de determinadas questões da contabilidade, percebeuse que Foucault está presente na maioria dos artigos de fundo teórico.

A necessidade de buscar respostas de questões que já não podem ser plenamente respondidas com as teorias comumente utilizadas no campo do conhecimento do pesquisador faz com que se busque preencher essas lacunas com teorias de outras áreas; a tentativa de inserção se dá pela via do diálogo entre o autor/ pesquisador e o autor/teórico.

Paralelamente, surgem os estudos aplicados, na tentativa de verificar a possibilidade de inserção da teoria no novo campo. Em segundo lugar, Foucault aparece em artigos na área de história da contabilidade e contabilidade organizacional e social, ou seja, relacionando-se diretamente com o campo em que foi produzido. Em menores quantidades foram encontradas as idéias de Foucault aplicadas à análise da contabilidade financeira, orçamentária, em accountability e na auditoria entre outros.

A ordem dos objetivos propostos foi alterada ao longo da pesquisa, uma vez que se verificou a impossibilidade de responder à questão de quais idéias de Foucault mais se inserem no campo contábil, sem antes conhecer o tipo de leitura. Tal impossibilidade é resultado dos diferentes tipos de leituras das obras de Foucault. Algumas leituras e referências superficiais não necessariamente significam que as idéias fundamentam as discussões. Seguindo as tipologias de Chartier (1985), definidas no início do trabalho, ou seja: a) apropriação incidental; b) apropriação conceitual tópica; e c) apropriação do modus operandi; decidiu-se pela utilização das apropriações conceituais tópicas e a de modus operandi em conjunto, considerando para análise a apropriação incidental e a apropriação tópica ou modus operandi. Ao longo da pesquisa, percebeu-se que a análise das duas tipologias separadamente requereriam uma descrição mais aprofundada das teorias de Michel Foucault, o que não é objetivo deste artigo. No entanto será objetivo de pesquisa futura. Os resultados revelaram que $40 \%$ dos artigos se referem à apropriação tópica, ou modus operandi, ou seja, seus autores incorporaram a sistemática de noções e conceitos de Michel Foucault em seus trabalhos.

As idéias extraídas da obra de Foucault que se tornaram pressupostos de pesquisa na área contábil, conforme mostra Tabela 5 foram: disciplina, poder 
disciplinar, vigilância e práticas de comportamento; discurso-linguagem-narrativa; discussões teóricas e estudos de casos aplicados; aspectos ligados à construção do conhecimento.

\section{Tabela 5: Tipo de Leitura e Idéias de Foucault Utilizadas}

\begin{tabular}{|l|l|l|l|l|}
\hline $\begin{array}{l}\text { a) apropriação } \\
\text { incidental }\end{array}$ & $\begin{array}{l}\mid \\
\text { b) apropriação conceitual tópica e c) apropriação do modus operandi }\end{array}$ \\
\hline $60 \%$ & \multicolumn{3}{|c|}{$40 \%$} \\
\cline { 2 - 4 } & \multicolumn{2}{|c|}{$52 \%$} & \multicolumn{1}{|c|}{$17 \%$} & $9 \%$ \\
\cline { 2 - 5 } & $\begin{array}{l}\text { disciplina, poder } \\
\text { disciplinar, } \\
\text { vigilância, e } \\
\text { práticas de } \\
\text { comportamento }\end{array}$ & $\begin{array}{l}\text { discurso- } \\
\text { linguagem- } \\
\text { narrativa }\end{array}$ & $\begin{array}{l}\text { discussões teóricas } \\
\text { e estudos de casos } \\
\text { aplicados. }\end{array}$ & $\begin{array}{l}\text { construção do } \\
\text { conhecimento }\end{array}$ \\
\cline { 2 - 5 } & $\begin{array}{l}\text { Surveiller et } \\
\text { Punir publicado } \\
\text { em 1975 }\end{array}$ & $\begin{array}{l}\text { L'ordre du } \\
\text { discours publicado } \\
\text { em 1971 }\end{array}$ & Várias obras & $\begin{array}{l}\text { L'Archéologie } \\
\text { du Savoir, } \\
\text { publicado em } \\
1969\end{array}$ \\
\hline
\end{tabular}

A partir deste resultado, foi possível verificar que $40 \%$ dos 113 artigos são fundamentados em Foucault. Desses, 52\% tratam do aspecto disciplinar da contabilidade, ou seja, a questão do poder disciplinar, da vigilância e das práticas de comportamento fundamentado em Surveiller et Punir publicado em 1975. São seguidos pela questão referente ao discurso-linguagem-narrativa (22\%), baseado principalmente em L'ordre du discours, publicado em 1971. Os aspectos ligados à construção do conhecimento contábil, baseado em L'Archéologie du Savoir, publicado em 1969, aparecem em menor quantidade (9\%). Finalmente, $17 \%$ apresentam discussões teóricas e estudos de casos aplicados. Os demais (60\%) são artigos que citam Foucault apenas como referência incidental ou tópica a conceitos.

\section{Análise da Metodologia de Pesquisa Utilizada pelos Autores}

A metodologia utilizada nos artigos foi classificada em três níveis; o nível 1 refere-se aos paradigmas, o 2 às estratégias e o 3 ao tipo de análise. A análise foi baseada nos conceitos e fases propostas por Denzin e Lincoln (2000).

Para cada nível, o modelo de análise da metodologia considerou os seguintes níveis: paradigmas, estratégias e métodos de análise.

Nível 1, Paradigmas: Teórico, Descritivo, Exploratório, Explicativo, Histórico, Causal e Outros. 
Nível 2, Estratégia: Estudo de Caso, Pesquisa de Campo, Empírico-Descritiva, Observação, Laboratório (Modelos), Bibliográfica e Outras.

Nível 3, Método de Análise: Interpretação, Crítica, Expositiva, Comprobatória, Estatística e Outras.

Tabela 6: Análise da Metodologia Utilizada nos Artigos

\begin{tabular}{|c|c|c|c|c|c|c|}
\hline \multirow[t]{2}{*}{ ARTIGOS } & \multicolumn{2}{|c|}{$\begin{array}{c}\text { Artigos } \\
\text { Fundamentados }\end{array}$} & \multicolumn{2}{|c|}{$\begin{array}{c}\text { Artigos com } \\
\text { Citações }\end{array}$} & \multicolumn{2}{|c|}{$\begin{array}{l}\text { Total de } \\
\text { Artigos }\end{array}$} \\
\hline & $\mathrm{N}^{\circ}$ & $\%$ & $\mathrm{~N}^{\mathrm{o}}$ & $\%$ & $\mathrm{~N}^{\circ}$ & $\%$ \\
\hline \multicolumn{7}{|l|}{ Nível 1: Paradigmas } \\
\hline - Teórico & 24 & 54,5 & 39 & 56,5 & 63 & 55,7 \\
\hline - Descritivo & 1 & 2,3 & 11 & 15,9 & 12 & 10,6 \\
\hline - Exploratório & 1 & 2,3 & 1 & 1,5 & 2 & 1,8 \\
\hline - Explicativo & 6 & 13,6 & 8 & 11,6 & 14 & 12,4 \\
\hline - Histórico & 12 & 27,3 & 10 & 14,5 & 22 & 19,5 \\
\hline - Causal & - & - & - & - & - & - \\
\hline - $\quad$ Outros & - & - & - & - & - & - \\
\hline Total & 44 & 100,0 & 69 & 100,0 & 113 & 100,0 \\
\hline \multicolumn{7}{|l|}{ Nível 2 : Estratégia } \\
\hline - $\quad$ Estudo de Caso & 10 & 22,7 & 20 & 29,0 & 30 & 26,5 \\
\hline - $\quad$ Pesquisa de Campo & - & - & 1 & 1,5 & 1 & 0,9 \\
\hline - Empírico-Descritiva & 1 & 2,3 & 1 & 1,5 & 2 & 1,8 \\
\hline - Observação & - & - & 3 & 4,3 & 3 & 2,7 \\
\hline - Laboratório (Modelos) & - & - & 1 & 1,5 & 1 & 0,9 \\
\hline - Bibliográfico & 33 & 75,0 & 41 & 59,4 & 74 & 65,4 \\
\hline - Outras & - & - & 2 & 2,8 & 2 & 1,8 \\
\hline Total & 44 & 100,0 & 69 & 100,0 & 113 & 100,0 \\
\hline \multicolumn{7}{|l|}{ Nível 3 : Análise } \\
\hline - Interpretação & 9 & 20,5 & 11 & 15,9 & 20 & 17,7 \\
\hline - Crítica & 27 & 61,3 & 37 & 53,7 & 64 & 56,6 \\
\hline - Expositiva & 7 & 15,9 & 21 & 30,4 & 28 & 24,8 \\
\hline - Comprobatória & 1 & 2,3 & - & - & 1 & 0,9 \\
\hline - Estatística & - & - & - & - & - & - \\
\hline - Outras & - & - & - & - & - & - \\
\hline Total & 44 & 100,0 & 69 & 100,0 & 113 & 100,0 \\
\hline
\end{tabular}


Conforme a Tabela 6, no caso da pesquisa em exame, observa-se no Nível 1, Paradigma, uma forte predominância dos estudos teóricos, tanto para os artigos fundamentados em Foucault (54,5\%), como para os que apenas o citam (56,5\%). Em seguida estão os estudos históricos, com $27,3 \%$ no primeiro caso e $14,5 \%$ no segundo.

No Nível 2 predominam os estudos bibliográficos, com 75,0\% no primeiro caso e 59,4\% no segundo, seguidos dos estudos de caso.

No Nível 3 a crítica constituiu o tipo de análise mais utilizado, uma vez que a maioria dos autores faz parte da área da contabilidade denominada Contabilidade Crítica.

\section{Classificações temáticas}

Para classificação dos temas abordados nos artigos decidiu-se pela utilização da classificação, utilizada anteriormente em Riccio, Carastan e Sakata (1999).

\section{Tabela 7: Classificações Temáticas}

\begin{tabular}{|l|c|c|c|c|c|c|}
\hline \multirow{2}{*}{ ARTIGOS } & \multicolumn{2}{|c|}{$\begin{array}{c}\text { Artigos } \\
\text { Fundamentados }\end{array}$} & \multicolumn{2}{c|}{$\begin{array}{c}\text { Artigos com } \\
\text { Citações }\end{array}$} & \multicolumn{2}{c|}{$\begin{array}{c}\text { Total de } \\
\text { Artigos }\end{array}$} \\
\cline { 2 - 7 } & $\mathrm{N}^{\circ}$ & $\%$ & $\mathrm{~N}^{\circ}$ & $\%$ & $\mathrm{~N}^{\circ}$ & $\%$ \\
\hline Temas & - & - & 7 & 10,1 & 7 & 6,2 \\
\hline Contabilidade Pública & 1 & 2,3 & - & - & 1 & 0,9 \\
\hline Cont. e Merc. de Capitais & 3 & 6,8 & 5 & 7,2 & 8 & 7,1 \\
\hline Contabilidade de Custos & 25 & 56,8 & 32 & 46,5 & 57 & 50,5 \\
\hline Contabilidade Gerencial & 1 & 2,3 & - & - & 1 & 0,9 \\
\hline Contabilidade Tributária & 11 & 25,0 & 13 & 18,8 & 24 & 21,2 \\
\hline Contabilidade Financeira & - & - & - & - & - & - \\
\hline Orçamento & - & - & - & - & - & - \\
\hline Capital Intelectual & 3 & 6,8 & 8 & 11,6 & 11 & 9,7 \\
\hline Aspectos Comportamentais & - & - & - & - & - & - \\
\hline Planejamento Financeiro & - & - & 4 & 5,8 & 4 & 3,5 \\
\hline Sistemas de Informação & 44 & 100,0 & 69 & 100,0 & 113 & 100,0 \\
\hline Total & & & & & & \\
\hline
\end{tabular}

Conforme se observa na Tabela 7, o tema predominante é o da Contabilidade Gerencial, tanto para os artigos fundamentados em Foucault, como para os que 
apenas citam o autor. Este resultado confirma que as obras de Foucault estão relacionadas, em grande parte, com a análise do poder.

\section{CONCLUSÃo}

Este artigo baseou-se na noção de campo científico para compreender como um autor entra no campo do conhecimento. Propôs-se verificar como se deu a inserção de Foucault na Contabilidade e quais as idéias do autor mais utilizadas como pressupostos de pesquisa.

Sob a perspectiva bibliométrica, este estudo revelou influência significativa das idéias de Foucault na pesquisa contábil, principalmente na visão da vertente que ficou conhecida como contabilidade crítica. Observa-se que esta influência está concentrada nas publicações européias, principalmente Accounting, Auditing \& Accountability Journal e Critical Perspectives on Accounting; fez-se sentir de forma mais contundente, a partir de 1992.

Em termos de produtividade, os autores que se dedicam ao tema apresentam comportamento bem próximo daquele que se pode inferir pela Lei de Lotka, mas inferior àquele constatado por Chung et al. (1992) para pesquisas em contabilidade de forma geral.

A pesquisa qualitativa baseada na leitura dos artigos revelou informações como a proximidade dos campos entre os quais a teoria é produzida e é recebida, bem como a grande receptividade por parte dos autores e a baixa recusa das idéias de Foucault.

A análise das metodologias de pesquisas utilizadas pelos diversos autores revelou que, quanto aos paradigmas, há forte predominância dos estudos teóricos, seguida pelos estudos históricos. Quanto à estratégia de pesquisa, predominam os estudos bibliográficos seguidos dos estudos de caso. O tipo de análise mais utilizado é a análise crítica.

A análise temática revelou que a Contabilidade Gerencial é o tema predominante $(50,5 \%)$ nos artigos, seguido pelos temas Contabilidade Financeira e Aspectos Comportamentais.

Nota-se que foram analisados apenas artigos já publicados em periódicos científicos, o que impossibilita identificar a real dificuldade de aceitação destes artigos por editores e pares. A partir desta análise dos 113 artigos, será possível formular hipóteses e questões para pesquisas futuras. 
Algumas questões colocadas por Bourdieu (1976) só poderiam ser respondidas pelo contato direto com os autores destes artigos, porquanto, segundo o autor, a inserção de um novo autor em uma área pode-se dar tanto por razões teóricas como por razões pessoais, como, por exemplo, a necessidade de reconhecimento como autoridade científica, ou para causar visibilidade e enfrentamento à lógica do sistema.

Quando um autor se torna indispensável ao nosso regime de leituras? Várias obras de Michel Foucault já estão disponíveis em língua portuguesa. Percebe-se, pela Internet, que Foucault já aparece em conteúdos de disciplinas de programas de contabilidade nos Estados Unidos e na Grã Bretanha. Pesquisa mais detalhada para verificar esta questão se faz necessária.

A análise das publicações realizada não permite resultados conclusivos acerca dos tipos de leituras feitos pelos pesquisadores. Pesquisa futura deverá definir as tipologias de Chartier (1985). Outra questão a ser respondida em pesquisas futuras, baseando-se em Gendron e Baker (2005), é: qual o suporte que os autores receberam de revistas além da AOS. É possível que existam periódicos que não constem da base de dados pesquisada; nem sempre os periódicos disponíveis na base de dados cobrem todo o horizonte de tempo em que o periódico foi publicado, o que constitui fator limitador do presente trabalho.

\section{Artigo submetido em 01.08.2005. Aprovado em 11.02.2006.}

\section{ReferênCias Bibliográficas}

Baxter, J., \&

Chua, W. F. (2003).

Alternative management accounting research - whence and whither. Accounting, Organizations and Society, 2(28), 97-126.

Birkin, F.,

Edwards, P., \&

Woodward, D. (2005).

Accounting's contribution to a conscious cultural evolution: an end to sustainable development. Critical Perspectives on Accounting 16(3), 185-208.
Booth, A. (2001).

Cochrane or cock-eyed? How should we conduct systematic reviews of qualitative research? Proceedings of the Qualitative Evidence-based Practice Conference, Taking a Critical Stance, Coventry University. Recuperado em $1^{\circ}$ March, 2005, de http://www.leeds.ac.uk/educol/ documents/00001724.htm

Bourdieu, P. (1976).

Le champ scientifique. Actes de la Recherche en Sciences Sociales, (2/3), 88-104. 
Bourdieu, P. (1997).

Que es hacer hablar a un autor? A propósito de Michel Foucault. In P. Bourdieu, Capital cultural, escuela y espacio social (Org.). México: Siglo Veinteuno.

Chartier, R. (Org.). (1985).

Pratiques de la lectur. Paris: Éditions Rivages.

Chua, W. F. (1986).

Radical developments in accounting thought. The Accounting Review, 61(4), 601-632.

Chung, K. H.,

Cox, R. A. K., \&

Pak, H. S. (1992).

Patterns of research output in the accounting literature: a study of the bibliometric distributions. Abacus, 28(2), 168-185.

Denzin, N., \&

Lincoln, Y. (Eds.). (2000).

Handbook of qualitative research (2nd ed.).Sage Publication: United States.

Gendron, Y., \&

Baker, C. (2005).

On interdisciplinary movements: the development of a network of support around foucaultian perspectives in accounting research. European Accounting Review, 14(3), 525-569.

Glass, G. V.,

McGaw, B., \&

Smith, M.L. (1981).

Meta-analysis in social research. Beverly Hills, CA: Sage.
Hoskin. K. W., \&

MaCve, R. H. (1986).

Accounting and the examination: a genealogy of disciplinary power. Organization and Society 11(2), 105-136.

Latour, B. (1987).

Science in Action. Cambridge, Mass: Harvard University Press.

Leal, R. P. C.,

Oliveira, J., \&

Soluri, A. F. (2003).

Perfil da pesquisa em finanças no Brasil. Revista de Administração de Empresas, 43(1), 91-103.

Lotka, A. J. (1926).

The frequency distribution of scientific productivity. Journal of the Washington Academy of Sciences, 16(12), 317-323.

Macias-Chapula, C. A. (1998).

O papel da informetria e da cienciometria e sua perspectiva nacional e internacional. Ciência da informação, 27(2), 134-140. Recuperado em 12 abril, 2004, de http:/ /www.unicamp.br/bc/RelSBU_online/ glossario/glossario.htm

Mcmillan, G. S., \&

Hamilton, R. D. (2000).

Using bibliometrics to measure firm knowledge: an analysis of the US pharmaceutical industry. Technology Analysis \& Strategic Management, 12(4), 465-475.

Mcmillan, G. S., \&

Hicks, D. (2001).

Science and corporate strategy: a bibliometric update of Hounshell and Smith. Technology Analysis \& Strategic Management, 13(4), 497-505. 
Oliveira, M. (2002).

Análise dos periódicos brasileiros de contabilidade, Revista Contabilidade \& Finanças, (29), 68-86.

Otchere, I. (2003).

Accounting and finance at forty: a retrospective evaluation. Accounting \& Finance, 43(2), 211-231.

Riahi-Belkaoui, A. (1997).

Research perspectives in accounting. Westport USA: Quorum Books.

Riccio, E. L.,

Carastan, J., \&

Sakata, M. C. G. (1999).

Accounting research in brazilian universities: 1962 - 1999. Caderno de Estudos, 11(22), 35-44.

Riccio, E. L.,

Sakata, M. C. G.,

Mendonça, O. R. de, \&

Cardoso, R. L. (2005).

Pesquisa científica em contabilidade entre 1990 e 2003. Revista de Administração de Empresas, 45(2), 34-45.

Shields, M. (1997).

Research in management accounting by north americans in the 1990s.
Journal of Management Accounting Research, 9(1), 3-61.

Tonelli, M. J.,

Caldas, M.,

Lacombe, B. M. B., \&

Tinoco, T. (2003).

Produção acadêmica em recursos humanos no Brasil: 1991-2000. Revista de Administração de Empresas, 43(1), 104-122.

Verbeek, A.,

Debackere, K.,

Luwel, M., \&

Zimmermann, E. (2002).

Measuring progress and evolution in science and technology - I: the multiple uses of bibliometric indicators. International Journal of Management Reviews, 4(2), 179-211.

Watts, R. L., \&

Zimmerman, J. L. (1990).

Positive accounting theory: a ten year perspective. The Accounting Review, 65(1), 131-156.

Wells, M. C. (1976).

A revolution in accounting thought? The Accounting Review, 51(3), 471482. 